Discussion Paper No. 01-21

\title{
Energy Taxes and Employment: A Do-it-yourself Simulation Model
}

Christoph Böhringer, Anna Ruocco and Wolfgang Wiegard 


\section{Non-technical summary}

Our paper deals with the welfare and employment effects of green tax reforms. In the first part we develop a flexible, interactive simulation model which is accessible under http://brw.zew.de. Users can specify their own green tax reforms or emission quotas and quantify welfare and employment effects. He or she can choose between different model variants, e. g. closed or small open economies with or without unemployment. In the second part we describe the numerical model specifications and explain some simulation calculations by means of examples. Some exercises for classroom use are available on the above mentioned web-site. 


\title{
Energy Taxes and Employment: A Do-it-yourself Simulation Model
}

\author{
Christoph Böhringer \\ Anna Ruocco \\ Wolfgang Wiegard
}

\section{Christoph Böhringer ${ }^{a}$ ZEW \\ P.O. Box 103443 \\ 68034 Mannheim \\ GERMANY}

boehringer@zew.de

\author{
Anna Ruocco ${ }^{b}$ \\ presso Centro Studi della \\ Confindustria \\ Viale dell' Astronomia, 30 \\ 00144 Rom \\ ITALY
}

A.Ruocco@confindustria.it
Wolfgang Wiegard ${ }^{\mathrm{c}}$

University of Regensburg

Department of Economics

93040 Regensburg

GERMANY

wolfgang.wiegard@wiwi.uni-regensburg.de

\footnotetext{
${ }^{a}$ Dr. Christoph Böhringer is Head of the department Environmental and Resource Economics at the Centre for European Economic Research (ZEW), Mannheim, Germany, and Lecturer at the University of Regensburg, Germany.

b Dr. Anna Ruocco is an economist at Confindustria, Rome, Italy, and on leave from the University of Regensburg, Germany.

${ }^{c}$ Professor Wolfgang Wiegard has a chair in economics at the University of Regensburg, Germany. He is a member of the German Council of Economic Experts.
} 


\section{Introduction}

The double or triple dividend issue is a controversially debated topic in environmental economics. On the one hand, there are numerous theoretical papers dealing with the environmental, welfare and employment effects of green tax reforms ${ }^{1}$. Unfortunately and according to our experience, only very few of them can be used in public finance or environmental economics courses at an undergraduate level, and some few more at a graduate level. After developing and working through all the equations of a general equilibrium model, students have to learn that analytical solutions almost never allow for clear-cut answers as to the welfare or employment effects, i. e. the second or third dividend, of environmental tax reforms. Furthermore, most tax scenarios considered are highly stylized and far from the complexities of real green taxes. A second class of papers uses small or large scale computable general equilibrium (CGE) models to evaluate the possibilities of multiple dividends of ecological tax reforms ${ }^{2}$. These models incorporate lots of details and come up with precise numbers concerning welfare and employment effects of introducing or changing green taxes. Once again, these approaches can hardly be used in classroom. As a rule, and mainly due to space constraints in scientific journals, there is neither a complete listing of the theoretical model underlying the numerical simulation nor of the data used to calibrate model parameters. As a consequence, CGE models come as a black box to non-expert readers. Without knowing the theoretical model, all they can do is believe or not believe the numerical results. Obviously, this is not the way to teach economics.

For the use in advanced undergraduate or graduate classes, we have developed a do-ityourself CGE simulation model which allows to examine the economic and environmental effects of a green tax reform, implemented recently in Germany. The policy problem is briefly described in the next section. Sections III and IV serve to explain the theoretical model and its numerical specification. Then we will present some comparative-static results regarding the implications of green tax reforms on employment and welfare. In this context, particular emphasis will be put on the economic explanation of the numerical results. Limited space is one of the reasons why only a few simulation calculations will be presented and commented on, but there is a way to study a huge number of additional tax reform measures: readers merely have to call our interactive simulation model under the web address http://... On this site we provide instructions on how to specify green tax reform packages or exogenous emission restrictions interactively. Our simulation model - written in the $\mathrm{GAMS}^{3}$ programming language and available in the source code on the Internet - then calculates the corresponding equilibria and shows the effects the specified tax reforms have on the wage

\footnotetext{
${ }^{1}$ See, for example, Pearce (1991), Bovenberg and de Mooij (1994a, 1994b), Goulder (1995), Oates (1995), Schneider (1997), or Bovenberg (1999).

${ }^{2}$ We only refer to Goulder $(1992,1994)$ and Bovenberg and Goulder $(1996,1997)$.

${ }^{3}$ GAMS is an acronym for Generic Algebraic Modeling System and has been developed for the analysis of economic-engineering problems at the World Bank. Our web-site provides a short tutorial to GAMS. The comprehensive GAMS handbook can be downloaded from the European website of the GAMS company at http://www.gams.de.
} 
rate, employment, welfare, energy consumption and other key variables. However, it is the reader's job to accomplish the step that is decisive for the economic analysis on his own: the economic explanation of the effects of the tax reforms he or she specified. The illustrative examples of explanations included for selected policy scenarios in section IV provide some orientation.

\section{The Policy Problem: Energy Taxation in Germany}

On April 1, 1999, the Ecological Tax Reform Law in Germany came into effect. The new law will progressively raise the energy tax at discrete intervals, and the additional energy tax revenue will be used to lower the contributions to pension insurance. In the first phase of the tax reform, taxes on fuels were raised by $6 \mathrm{DM}^{4}$ per hectoliter, heating oil by $4 \mathrm{DM}$ per hectoliter, natural gas by $0.32 \mathrm{DM} / \mathrm{MWh}$, and electricity by $2 \mathrm{DM} / \mathrm{MWh}$; in return, the amount of pension contributions was reduced by $0.8 \%$ for both employers and employees. By now, the third phase of the ecological tax reform, which further raises taxes on mineral oil and electricity, has taken effect.

The green tax reform aims at cutting energy consumption and reducing the associated harmful emissions (especially $\mathrm{CO}_{2}$ emissions), but also at decreasing labor costs, thus providing incentives to create new jobs.

Fears that the reform might jeopardize the international competitiveness of German companies have led to far-reaching special provisions. Originally, 27 energy-intensive industries were to be exempted from the energy taxes. But the EU-commission had reservations about the plan, since it believed that the plan unduly favored parts of the German production sector. Thus, direct tax exemptions were replaced by compensatory regulations for energy-intensive companies to keep their actual tax burden constant, once a certain threshold value is reached. The environmental effectiveness of the current tax reform is, therefore, restricted to companies which consume less than that threshold value or have an economic incentive to reduce their energy consumption below it.

We want to know: What is the environmental effectiveness of this tax reform? Is there a second or a third dividend, i. e. does the green tax reform contribute to reduce excess burdens of the tax system $\left(2^{\text {nd }}\right.$ dividend $)$ and does it alleviate unemployment $\left(3^{\text {rd }}\right.$ dividend $)$ ? To answer these questions, we develop and numerically specify a simple general equilibrium model. We are particularly interested in a comprehensive sensitivity analysis of results with respect to changes in the tax reform design and alternative macroeconomic hypothesis.

\footnotetext{
${ }^{4} \mathrm{DM}$ is the German currency unit, with a current exchange rate of $2.10 \mathrm{DM} / \$$. The DM will be replaced by Euro
} bills in 2002 . 


\section{The Theoretical Model}

An appropriate analysis of the effects induced by green tax reforms requires the careful specification of several key model elements: different energy tax rates in the private and production sectors must be jointly represented with other initial tax distortions; the phenomenon of unemployment needs to be endogenously explained; finally, alternative possibilities of the use of the energy tax revenue have to be taken into consideration and incorporated within the model.

\section{Household Sector}

In our model, $E_{H}$ denotes the use of energy in the private sector and $E_{\mathrm{Y}}$ the use of energy for the production of good $Y$. For simplification, we assume a representative household which demands - besides energy $E_{H}$ - an aggregate consumption good $X$, leisure $F$ and a free public good $G$. The utility associated with the consumption of these goods is captured by the function $u\left(X, E_{H}, F, G\right)$, where all first partial derivatives are positive.

The overall consumption of energy in the economy $\left(E_{H}+E_{Y}\right)$ and the accompanying harmful emissions which cause environmental damages are represented by means of an environmental damage function $v\left(E_{H}+E_{Y}\right)$ with $v^{\prime}<0$. It is implicitly assumed that the connection between energy use and emissions is linear. Additive linking of the functions $u(\cdot)$ and $v(\cdot)$ results in the utility $U$ of the representative household, which is:

$$
U=u\left(X, E_{H}, F, G\right)+v\left(E_{H}+E_{Y}\right) .
$$

Taking the budget constraint

$$
p_{X} X+p_{E} E_{H}+w\left(1-\tau_{w}\right) F=w\left(1-\tau_{w}\right) \bar{F}+r\left(1-\tau_{K}^{R}\right) \bar{K}+B
$$

into account, the household chooses the quantities $X, E_{H}$ and $F$ in order to maximize its utility $U$. The consumer prices for the goods $X$ and $E_{H}$ are denoted by $p_{X}$ and $p_{E}, w$ is the wage rate, $\tau_{w}$ denotes the labor tax rate, $\tau_{K}^{R}$ is the tax rate on capital income ${ }^{5}$ and $r$ indicates the interest rate. $\bar{F}$ and $\bar{K}$ are given exogenously and denote the endowment with time and capital, respectively. $(\bar{F}-F)=L^{S}$ is then the labor supply. The household receives additional income $B$ from transfers which will be explained later. We assume that consumers neglect the contribution of their individual energy consumption to the overall energy consumption $\left(E_{H}+E_{Y}\right)$. Of course, this assumption only makes sense if the representative household can be considered an aggregate of many identical households. Together with the additivity property of the utility function, the assumption ensures that the overall energy

\footnotetext{
${ }^{5}$ The superscript index indicates the ,residence principle“. The differentiation between a capital tax according to the ,residence principle“ and according to the ,source principle“ is only relevant in an open economy.
} 
consumption of the economy leaves the household decisions unaffected. The solution to the household's optimization problem generates demand functions for $X$ and $E_{H}$ as well as leisure demand $F$ (i. e. also the labor supply function), each depending on consumer prices and household income from capital endowment $r\left(1-\tau_{K}^{R}\right) \bar{K}$ and transfers $B$ :

$$
(3 \mathrm{a}-\mathrm{c}) \quad X=X\left(p_{X}, p_{E}, w\left(1-\tau_{w}\right), r\left(1-\tau_{K}^{R}\right) \bar{K}, B\right) ; \quad E^{H}=E^{H}(.) ; \quad F=F(\cdot) .
$$

The provision of the public good is kept constant (see equation 15) and, therefore, need not be included as an argument of the demand function.

\section{Production Sector}

We distinguish three sectors on the production side of the economy. The consumer goods industry produces the output $Y$ with inputs capital $\left(K_{Y}\right)$, labor $\left(L_{Y}\right)$ and energy $\left(E_{Y}\right)$, subject to the following linear-homogenous production function:

$$
Y=f_{Y}\left(K_{Y}, L_{Y}, E_{Y}\right)
$$

Linear-homogenous production functions also apply for domestic energy production $E$ and the production of the public good:

$$
E=f_{E}\left(K_{E}, L_{E}\right)
$$

(6) $G=f_{G}\left(K_{G}, L_{G}\right)$.

It would be possible to represent the use of energy as a separate production factor, but this is not necessary for our purposes.

Within our model, we allow for the taxation of all factors. The tax rate on the use of energy in the consumer goods sector is represented by $\tau_{E}^{Y}$; labor and capital may get taxed at sectorally uniform rates $\tau_{L}$ and $\tau_{K}^{S}$, where the index "S" stands for "source principle". Under perfect competition on all goods markets, the economic rent is zero and the zero-profit condition for each of the three production sectors is:

$$
\begin{aligned}
& q_{Y} Y=w\left(1+\tau_{L}\right) L_{Y}+r\left(1+\tau_{K}^{S}\right) K_{Y}+q_{E}\left(1+\tau_{E}^{Y}\right) E_{Y} \\
& q_{E} E=w\left(1+\tau_{L}\right) L_{E}+r\left(1+\tau_{K}^{S}\right) K_{E} \\
& q_{G} G=w\left(1+\tau_{L}\right) L_{G}+r\left(1+\tau_{K}^{S}\right) K_{G} .
\end{aligned}
$$


Here $q_{Y}, q_{E}$ and $q_{G}$ denote the producer prices. Cost-minimization generates the following factor demand functions:

$$
\begin{array}{ll}
(10 \mathrm{a}-\mathrm{c}) & L_{Y}=L_{Y}\left(w\left(1+\tau_{L}\right), r\left(1+\tau_{K}^{S}\right), q_{E}\left(1+\tau_{E}^{Y}\right), Y\right) \quad K_{Y}=K_{Y}(\cdot) ; \quad E_{Y}=E_{Y}(\cdot), \\
(11 \mathrm{a}-\mathrm{b}) & L_{E}=L_{E}\left(w\left(1+\tau_{L}\right), r\left(1+\tau_{K}^{S}\right), E\right) \quad K_{E}=K_{E}(\cdot), \\
(12 \mathrm{a}-\mathrm{b}) & L_{G}=L_{G}\left(w\left(1+\tau_{L}\right), r\left(1+\tau_{K}^{S}\right), G\right) \quad K_{G}=K_{G}(\cdot) .
\end{array}
$$

It would also be possible to work on a per capita basis and to derive factor demand functions, as well as supply functions for goods from profit-maximization.

The relationships between producer and consumer prices for energy and the aggregate consumer good are given by:

$$
p_{X}=\left(1+\tau_{C}\right) q_{Y} ; \quad p_{E}=\left(1+\tau_{C}\right)\left(1+\tau_{E}^{H}\right) q_{E}
$$

where $\tau_{C}$ represents a uniform consumption tax rate and $\tau_{E}^{H}$ the tax on energy consumption by private households.

The tax base of the consumption tax, thus, includes the energy tax.

\section{Public Sector}

In a static model, current expenditure and tax revenues of the public sector have to be equal. The budget equation is:

$$
\begin{aligned}
q_{G} G+B= & \tau_{C}\left[q_{Y} X+q_{E}\left(1+\tau_{E}^{H}\right) E_{H}\right]+\tau_{w} w(\bar{F}-F) \\
& +\tau_{L} w\left(L_{Y}+L_{E}+L_{G}\right)+\tau_{K}^{S} r\left(K_{Y}+K_{E}+K_{G}\right)+\tau_{K}^{R} r \bar{K} \\
& +\tau_{E}^{H} q_{E} E_{H}+\tau_{E}^{Y} q_{E} E_{Y} .
\end{aligned}
$$

The left hand side of this equation shows the expenditure for the provision of public goods and the transfers to households. The terms on the right hand side correspond to the government revenues from the general consumption tax, the labor income tax, from taxes on the use of labor and from the capital income tax according to the source and the residence principle, as well as from the tax on the energy consumption of private households and on the use of energy for the production of consumer goods. Finally, for simplicity we assume that the public good is provided at a constant quantity: 


$$
\text { (15) } G=\bar{G}
$$

\section{Market Equilibrium Conditions}

The formulation of the market equilibrium conditions depends on the foreign closure of the model (closed economy versus small open economy) and the specification of the labor market (full employment versus unemployment). Below, the associated four different variants will be discussed. Our paper puts emphasis on the basic understanding of economic mechanisms. By comparing the four different model variants, the dependence of results on the models' structural assumptions becomes clear. Table 1 summarizes the key settings for the model variants.

Table 1: $\quad$ Classification of model variants

\begin{tabular}{|l|ll|}
\hline & Full Employment (FE) & Unemployment (UE) \\
\hline Closed Economy (CE) & CE-FE & CE-UE \\
Small Open Economy (SOE) & SOE-FE & SOE-UE \\
\hline
\end{tabular}

In the following sections, we will discuss the market equilibrium conditions for the different model specifications.

\section{a) CE-FE}

Market equilibrium for the closed economy with full employment is determined by the following set of equations:

(18) $\bar{K}=K_{Y}+K_{E}+K_{G}$

(19) $\left(L^{S} \equiv\right) \bar{F}-F=L_{Y}+L_{E}+L_{G}(\equiv L)$

In equation (19) $L^{S}$ denotes the labor supply and $L$ the labor demand. 
According to Walras' Law, we can drop one of the market equilibrium conditions and fix one price as a numeraire. We ignore the capital market equilibrium condition (18) and set the interest rate $r$ equal to 1 .

\section{b) SOE-FE}

For the small open economy, we assume that capital is mobile across domestic borders and that energy can be traded internationally while the consumer goods $X$ can not. With respect to taxation of energy consumption, the destination principle applies. Equations (17) and (18) must then be replaced by the following balance of payments condition:

$$
q_{E}\left(E-E_{H}-E_{Y}\right)+r\left(\bar{K}-K_{Y}-K_{E}-K_{G}\right)=0 .
$$

The first term on the left hand side concerns the trade balance and the second term summarizes the capital income flows between the domestic economy and abroad, which are reported in the balance of services. In equilibrium, the trade deficit (trade surplus) must equal the inflow (outflow) of capital income. Full employment is still characterized by equation (19). In the small open economy, the prices of traded goods and factors, i.e. $q_{E}$ and $r$, are exogenously determined on the world markets. Note that equation (20) is automatically fulfilled as a consequence of Walras' Law.

\section{c) CE-UE and SOE-UE}

One objective of the green tax reform is the reduction of unemployment. In the relevant literature, this potential effect is often referred to as "second" or "third dividend". In both of our unemployment model variants (indicated by the suffix "-UE"), we will investigate the impact of the green tax reform on the level of unemployment. We introduce unemployment through the specification of a "wage curve", which postulates a negative relationship between the real wage rate and the rate of unemployment:

$$
\frac{w}{P}=g(u r) \quad \text { with } g^{\prime}<0,
$$

where $P$ denotes a consumer goods price index

$$
P=P\left(p_{X}, p_{E}\right)
$$

and $\operatorname{ur}\left(\equiv\left(L^{S}-L\right) / L^{S}\right)$ is the unemployment rate. This type of wage curve can be derived from trade union wage models, as well as from efficiency wage models (see e. g. Hutton and Ruocco, 1999). 
Figure 1 illustrates the wage curve in the traditional labor market diagram (rather than in the $u r-w / P$-space). The real wage rate $w / P$ is measured on the vertical axis and the labor supplied and demanded are measured on the horizontal axis.

Figure 1: Wage curve and unemployment

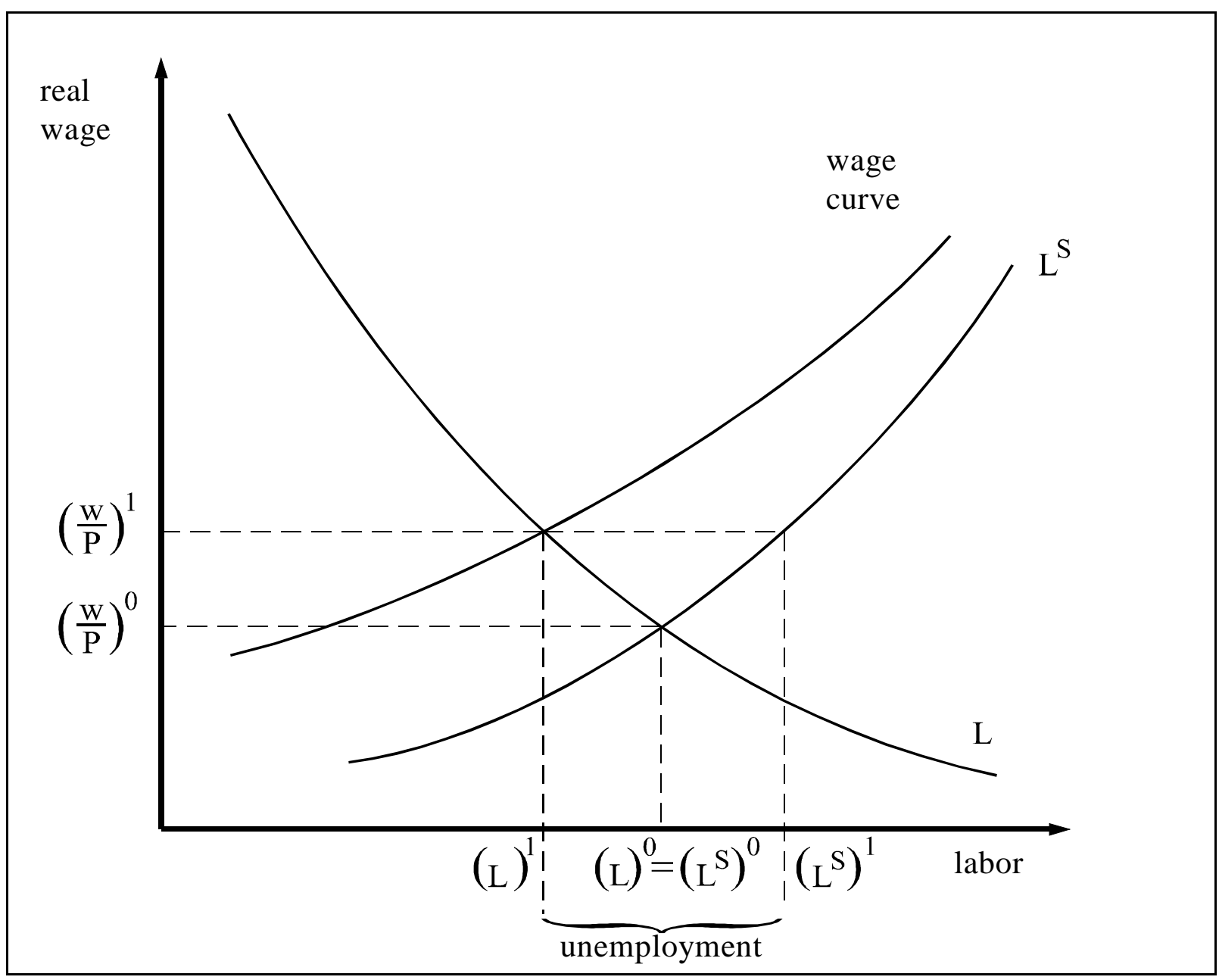

Full employment occurs with the real wage rate of $(w / P)^{0}$ at the intersection of the (inverse) labor demand function $L$ and the labor supply function $L^{S}$. The wage curve now replaces the labor supply curve. Consequently, the equilibrium wage rate $(w / P)^{1}$ lies above the market clearing wage rate. This causes unemployment at an amount of $\left(L^{S}\right)^{1}-(L)^{1}$.

Taking taxes and unemployment benefits into account, the wage curve can be specified stating a negative relationship between the unemployment rate $u r$ and the net wage rate:

$$
\frac{w \rho}{P}=g(u r, B) \quad \text { with } g^{\prime}<0,
$$

where: $\rho \equiv \frac{1-\tau_{w}}{1+\tau_{L}}$ 
The resulting expression $(1-\rho)$ indicates the tax wedge between the employers' gross wage costs and the employees' net wages.

Instead of equation (19), the following equilibrium condition for the labor market then applies:

$$
L=L^{S}(1-u r)
$$

In our model variants with unemployment, we interpret the transfers to the private household sector which enter their budget equation as unemployment benefits. Following Koskela and Schöb (1999), the employment effects of a green tax reform depend crucially on the form of these transfer payments. Here we assume that the unemployment benefit payments $\overline{B_{r}}$ are constant in real terms and are not taxed. The relationship between nominal and real unemployment benefits is given by:

$$
B=P \overline{B_{r}} L^{S} u r
$$

With these assumptions, we obtain a simple specification of the wage curve as a log-linear function (Hutton and Ruocco, 1999, p. 273):

(24) $\log \left(\frac{w}{P}\right)=\gamma_{0}+\gamma_{1} \log (u r)-\log \rho$

where $\gamma_{0}$ is a positive scale parameter and $\gamma_{1}<0$ indicates the elasticity of the real wage with respect to the unemployment rate. Real unemployment benefits are included in the parameter $\gamma_{0}$.

If the household gets rationed on the labor market, the budget restriction changes in so far as the actual net wage income is determined by $w\left(1-\tau_{w}\right) L$ and no longer by $w\left(1-\tau_{w}\right)(\bar{F}-F)$. Determination of welfare effects is also based on enforced (rather than voluntary) leisure consumption. The details of welfare measurement for rationed goods can be found in Johansson (1987, chapter 5). In our model variants with full employment, we also assume transfers in real terms. These, however, are constant and do not vary with the rate of unemployment. Equation (23) simply becomes:

$$
B=P \bar{B} r
$$

For the sake of transparency, let us summarize at the end of this section once more which variants of the model are specified through which equations, and which variables are to be determined endogenously. 
All variants of the model have 18 equations and 18 endogenous variables in common. These are equations (3a-c), (4), (5), (6), (10a-c), (11a-b), (12a-b), (13a-b), (14), (15), (21), and variables $X, E_{H}, F, Y, E, G, L_{Y}, K_{Y}, E_{Y}, L_{E}, K_{E}, L_{G}, K_{G}, p_{X}, p_{E}, P$ as well as the endogenous equal-yield tax rate, for example $\tau_{\mathrm{w}}$. Table 2 provides an overview of the additional equations and variables that are model-specific.

Table 2: $\quad$ Model-specific equations and variables

\begin{tabular}{|c|c|c|}
\hline CE & FE & UE \\
\hline \multirow{2}{*}{ SOE } & $(16),(17),(19),(25)$ & $(16),(17),(22),(24),(23)$ \\
& $q_{X}, q_{E}, w, B$ & $q_{X}, q_{E}, w, u r, B$ \\
\hline & $(19),(25)$ & $(22),(24),(23)$ \\
& & $w, u r, B$ \\
\hline
\end{tabular}

\section{Numerical Model Specifications}

Analytically, the economic and environmental implications of a green tax reform can be studied in a comparative-static framework. For example, one could derive the total differentials of the market equilibrium conditions and solve this system of equations for the relative changes in the variables of interest. This is the normal procedure employed in the theoretical literature (see e.g. Bovenberg and de Mooij (1994a,b) or Schneider (1997)). Although our model is a radical simplification of the real economy, it is still so complicated that an analytical solution would not deliver any results for a sound economic interpretation. Simulation analyses on a numerical basis provide an alternative. For this type of analysis, we must first specify the concrete functional forms for the utility function and the cost functions, and fix the values of the model parameters as well as of the exogenous variables. A specific data set then corresponds to a specific benchmark equilibrium. Within the policy simulations single parameters or exogenous variables are changed and a new (counterfactual) equilibrium is computed. Comparison of the counterfactual and the benchmark equilibrium then yields information on the policy-induced changes of economic variables such as employment, production, welfare, relative prices, etc. 
In general, there are two approaches for the model parameterization. On the one hand, one could take exogenous values for all parameters and exogenous variables and then solve the system of non-linear equations for the benchmark equilibrium. However, for the same set of parameter values one would determine four different benchmark equilibria - one for each variant of the model. Taking the different benchmark equilibria as starting (reference) points, one would then perform numerically one (or more) comparative-static simulations. Yet, a cross-comparison of results for the different variants with respect to some tax reform measure would then hardly make sense. For this reason, another approach will be adopted here. We assume that the same benchmark equilibrium underlies all of our four model variants. In principle, one could construct such a benchmark equilibrium from the national accounts and other statistics (such as input-output tables) of the benchmark year. In this paper, we are not interested in the explanation of observed data, but in the better understanding of economic mechanisms. For this purpose, it is sufficient simply to employ stylized data as provided by Table 3.

If the benchmark equilibrium is the same for all model variants, they must differ from each other in other ways. By definition, the benchmark equilibrium must correspond to the numerical solution for each model variant. This is guaranteed by a sufficiently large number of parameters, which are endogenously determined for each variant, so that the quantities and prices of the benchmark equilibrium are replicated with these parameters as the numerical solution of the respective model variant. In the literature this procedure is called calibration (see e.g. Mansur and Whalley, 1984). Typically, the number of all model parameters is larger than the number of model equations, and we will have to fix the remaining "free" parameters (e. g. elasticities of substitution across inputs in production).

Table 3 describes our benchmark equilibrium in terms of a social accounting matrix (King 1985). The upper section contains the benchmark prices and tax rates, the lower section reports the benchmark quantities, labor income tax revenues and transfers.

For the sake of transparency, we have indicated the equation references (see section III) for the market equilibrium conditions associated with the rows (market clearance) and columns (zero profit for production sectors, income balance for household and government) on the edges of the social accounting matrix. In general, data consistency of a social accounting matrix requires that the sums of each of the rows and columns equal zero.

Note that the benchmark equilibrium given in Table 3 is the same for all four variants of the model developed in section III. This means that there is no trade at the benchmark for the small open economy. Exports and imports of capital and goods will then only be induced when tax reform measures are undertaken. In the model variant with unemployment, the value at the intersection of the "L"-row and the "Household"-column indicates rationed labor supply (see equation (24)). 
Table 3: $\quad$ Prices and quantities in the benchmark equilibrium

Prices

$$
q_{X}=q_{Y}=q_{E}=r=w=1.0
$$

\section{Social Accounting Matrix}

$\begin{array}{lll}\text { Y } & \text { G } \quad \text { Household Government } & \text { Eq.-No. } \\ \text { CE-FE }\end{array}$

$\mathrm{X}-25$

E

5

$-15$

$-8$

3

$-27$

$5-16$

K

6

5

B

Eq.-No.

(7)

(8)

(9)
8

9

$-9$

(2)

$\begin{array}{ll}-1 & 1\end{array}$

The utility and production functions have yet to be specified. In principle, there is the choice among various functional forms which just have to exhibit certain mathematical properties (we will not elaborate on these here). In most of the relevant literature, however, the functional forms employed belong to the type of constant-elasticity-of-substitution (CES) functions. Such functions have certain mathematical properties (regularity) that ease the numerical analysis considerably, but are still flexible enough to allow for the appropriate representation of economic behavior. Table 4 summarizes our choices of functional forms.

The utility function is represented by a so-called "utility tree". At the bottom level, we aggregate the consumption of the goods $X$ and $E_{H}$ to an aggregate consumption good $C$, which 
is then combined with leisure demand $F$ at the top level. The resulting utility function is weakly separable in goods $X$ and $E_{H}$, and leisure $F$. Both "utility branches" are represented by CES functions. The parameters $\pi_{C}$ and $\pi_{U}$ correspond to the substitution elasticities between $X$ and $E_{H}$, and between $C$ and $F$, respectively; in illustrative terms, these elasticities indicate the curvature of the indifference curve in the $X-E_{H}$ space as well as in the $C-F$-space. The parameters $\beta_{C}$ and $\beta_{F}$ are called share parameters. Because the provision of the public good was assumed to be constant, it can be omitted from the utility function $u(\cdot)$ without loss of relevant information. The equation for the consumer price index follows from the underlying CES utility function over $X$ and $E_{H}$. Also, we employ CES-functions to characterize the production functions. In the production of the consumption good, capital and labor are combined at the bottom level to yield value-added $Q\left(K_{Y}, L_{Y}\right)$, whereas at the top level valueadded $Q$ and intermediate energy $E_{Y}$ are combined to yield output $Y$. The substitution elasticities are represented here with $\sigma$, and the share parameters with $\alpha$, where the indices in subscript refer to the production sector.

The environmental damage function is given by the lower section of Table 4 . The concrete functional form (which has no empirical foundation) has been specified in such a way that the implied marginal damage function $\left(-v^{\prime}\right)$ is linear and exhibits a positive gradient. Finally, we provide the wage curve which has already been stated in equation (24).

In addition to the functional forms, the above mentioned "free" parameters, as well as the values for the exogenous variables of the model, must be determined. This must be done carefully. On the one hand, the CES functions turn into a Cobb-Douglas specification for certain parameter values (this applies to $\pi_{C}=1$ or $\sigma=1$, for example), and this must be taken into consideration with respect to the analytical formulation. On the other hand, certain parameter combinations may not lead to solutions at all, or just deliver solutions which do not make sense from an economic point of view.

The values for parameters or exogenous variables, specified in the last row and column of Table 4, were selected so that the benchmark equilibrium in Table 3 exhibits economically meaningful characteristics. One example would be that the labor supply elasticity with respect to the real wage rate takes on a plausible value. ${ }^{6}$ Another example for the reasonable choice of values would be that the economy in the benchmark equilibrium is on the rising branch of the Laffer-curve. Although the free parameter values for all four models are identical, the remaining parameters for each model are calibrated so that the solution of the numerically specified theoretical model replicates the benchmark equilibrium shown in Table 3.

\footnotetext{
${ }^{6}$ We have chosen a value of 0.2 for the labor supply elasticity at the benchmark, which, although a little high, is not implausible.
} 
Table 4: $\quad$ Functional forms and values for the free parameters

\begin{tabular}{|c|c|c|}
\hline & Functional Form & Parameter Values \\
\hline $\begin{array}{l}\text { Utility Function } \\
u(C(X, E), F)\end{array}$ & $\begin{array}{l}C=\left[\beta_{X}^{1 / \pi_{C}} X^{\Omega_{C}}+\left(1-\beta_{X}\right)^{1 / \pi_{C}} E_{H}^{\Omega_{C}}\right]^{1 / \Omega_{C}} \\
\operatorname{mit} \Omega_{C}=\left(\pi_{C}-1\right) / \pi_{C} \\
u=\left[\beta_{C}^{1 / \pi_{u}} C^{\Omega_{u}}+\left(1-\beta_{C}\right)^{1 / \pi_{u}} F^{\Omega_{u}}\right]^{1 / \Omega_{u}} \\
\operatorname{mit} \Omega_{u}=\left(\pi_{u}-1\right) / \pi_{u}\end{array}$ & $\begin{array}{l}\pi_{C}=1.1 \\
\pi_{u}=0.884 \text { (calibrated) }\end{array}$ \\
\hline $\begin{array}{l}\text { Consumer goods price } \\
\text { index } \\
P\left(p_{X}, p_{E}\right)\end{array}$ & $P=\left[\beta_{X} p_{X}^{1-\pi_{C}}+\left(1-\beta_{X}\right) p_{E}^{1-\pi_{C}}\right]^{\frac{1}{1-\pi_{C}}}$ & \\
\hline $\begin{array}{l}\text { Production function } \\
E=f_{E}\left(K_{E}, L_{E}\right) \\
G=f_{G}\left(K_{G}, L_{G}\right) \\
Y=f_{Y}\left(Q(K, L), E_{Y}\right)\end{array}$ & $\begin{array}{l}E=\left[\alpha_{E}^{1 / \sigma_{E}} K_{E}^{\theta_{E}}+\left(1-\alpha_{E}\right)^{1 / \sigma_{E}} L_{E}^{\theta_{E}}\right]^{1 / \theta_{E}} \\
\text { where } \theta_{E}=\left(\sigma_{E}-1\right) / \sigma_{E} \\
G=\left[\alpha_{G}^{1 / \sigma_{G}} K_{G}^{\theta_{G}}+\left(1-\alpha_{G}\right)^{1 / \sigma_{G}} L_{G}^{\theta_{G}}\right]^{1 / \theta_{G}} \\
\text { where } \theta_{G}=\left(\sigma_{G}-1\right) / \sigma_{G} \\
Q=\left[\alpha_{Q}^{1 / \sigma_{Q}} K_{Y}^{\theta_{Q}}+\left(1-\alpha_{Q}\right)^{1 / \sigma_{Q}} L_{Y}^{\theta_{Q}}\right]^{1 / \theta_{Q}} \\
\text { where } \theta_{Q}=\left(\sigma_{Q}-1\right) / \sigma_{Q} \\
Y=\left[\alpha_{Y}^{1 / \sigma_{Y}} Q^{\theta_{Y}}+\left(1-\alpha_{Y}\right)^{1 / \sigma_{Y}} E_{Y}^{\theta_{Y}}\right]^{1 / \theta_{Y}} \\
\text { where } \theta_{Y}=\left(\sigma_{Y}-1\right) / \sigma_{Y}\end{array}$ & $\begin{array}{l}\sigma_{E}=0.8 \\
\sigma_{G}=0.98 \\
\sigma_{Q}=0.68 \\
\sigma_{Y}=0.7\end{array}$ \\
\hline $\begin{array}{l}\text { Environmental damage } \\
\text { function } u(E)\end{array}$ & $u=A-\frac{\gamma}{2} E^{2}$ & $A=10, \quad \gamma=0.1$ \\
\hline $\begin{array}{l}\text { Wage curve } \\
\frac{w \theta}{P}=g(u r)\end{array}$ & $\log \left(\frac{w}{P}\right)=\gamma_{0}+\gamma_{1} \log (u r)-\log \theta$ & $\gamma_{1}=0.5$ \\
\hline Exogenous variable & \multicolumn{2}{|c|}{$\begin{array}{l}\bar{K}=16 ; \quad \overline{\mathrm{G}}=8 ; \bar{F}=47.5 \text { (calibrated }- \text { full employment case) } \\
\bar{F}=52.5 \text { (calibrated }- \text { unemployment case with initial } u r=0.1 \text { ) }\end{array}$} \\
\hline
\end{tabular}




\section{Simulation Results and Economic Interpretation}

\section{First, Second and Third Dividend of a Green Tax Reform}

In this section, we will present and discuss our simulation results. In doing so, it is important to remember that the exact numerical values have no major meaning. For this reason, we will draw only qualitative conclusions based on the numerical results. We will see that some insights are rather surprising. This is precisely the advantage of our simulation model: through comparative-static exercises we gain qualitative (general) insights that could hardly be derived at by analytical manipulations, no matter how tricky they might be.

Numerical results and interpretations for certain tax reforms will be discussed in more detail only for the model variants CE-FE and CE-UE (closed economy with full employment and closed economy with unemployment). The other model variants - SOE-FE and SOE-UE could be analyzed parallel to this. It is also possible to investigate further tax reform packages for each of these model variants. We will leave this up to the interested reader. In this paper, we are only offering the general tools and the instructions, and illustrate along some examples how to gain economic insights using our simulation model. The rest will have to be done by the reader himself. This is, after all, a do-it-yourself simulation model.

It should be the primary goal of a green tax reform to achieve positive environmental effects, e.g. via the reduction of harmful emissions from fossil fuel combustion. This effect will be called the first dividend (D1) of a green tax. In addition to that, a green tax reform is said to have other positive effects. Supporters of a green tax reform hope for a "better" and more efficient tax system due to the swap of green taxes for existing distorting taxes. The literature refers to this as second dividend (D2). Finally, it is believed that employment gains could be achieved if the tax revenue is used to reduce the tax burden on labour. In the case of positive employment effects, a green tax would then cause a third dividend (D3).

Based on our simulation model, one can identify under which conditions one or more of these dividends will occur. The dividends have to be quantified, i.e. measured. This will be easiest with respect to the employment effects. In this context, the third dividend is simply calculated as the change in the employment rate in percentage points. For example, would the unemployment rate be reduced from 10 per cent in the benchmark equilibrium ( $u r=0.1)$ to 8 per cent ( $u r=0.08$ ) due to a green tax reform, the accounted value for D3 would be "-2.000". Unemployment would be reduced by 2 percentage points. Similarly, a value of " 1.500 " for D3 would imply an increase in unemployment by 1.5 percentage points.

Methodologically clear, however, conceptionally more difficult is the measurement of the second dividend of a green tax reform. In the public finance literature, the efficiency properties of a tax system are picked up by the the so-called excess burden. The latter can be 
calculated by using the Hicksian equivalent variation. With revenue neutral tax reforms - we restrict ourselves to those - the excess burden corresponds to the income change (in units of the numéraire good), which a representative consumer has to bear, due to the tax reform. The second dividend is positive if it improves the income situation.

The measurement of the first dividend is problematic. The taxation of energy should lead to a reduced energy consumption and, therefore, to a reduction in harmful emissions. For simplicity we assume a constant relationship between pollutants and energy consumption. The first dividend could then simply be defined as the percentage change of the overall energy consumption of domestic households and production. This setting reflects the prevailing public focus in the policy debate on concrete emission reduction targets. In the context of its climate protection program, Germany has accepted the liability to reduce $\mathrm{CO}_{2}$ emissions by 25 per cent until 2005 (compared to 1990 emission levels). We will speak of D1(P) when having this interpretation of the first dividend in mind, where $\mathrm{P}$ stands for a percentage reduction in quantity. A value of " -10.000 " would indicate a 10 percent reduction of the domestic energy consumption. The reduction of harmful emissions, which is closely connected to the reduction of energy consumption, is not an end in itself. After all, there is an optimal environmental pollution and further reductions of harmful emissions would result in a welfare reduction. What really matters are the welfare effects of a change in harmful emissions. Due to the lack of exact empirical information on damage functions and the valuation of environmental damages, welfare effects can hardly be determined empirically. We have assumed a simple - and admittedly a somewhat arbitrary - environmental damage function $v\left(E_{H}+E_{Y}\right)$ to show that welfare effects, not quantity effects, matter. The first dividend, measured by the welfare effects of the environmental policy, is characterized by the notation D1(W) (W for welfare). Note that D1(W) and D1(P) are connected via a monotonous transformation.

The HEV can be broke down into two components for our utility function:

$$
H E V^{j}=\underbrace{\left(\frac{u^{j}-u^{0}}{u^{0}} Y^{0} \frac{u^{0}}{U^{0}}\right)}_{D 2}+\underbrace{\left(\frac{v^{j}-v^{0}}{v^{0}} Y^{0} \frac{v^{0}}{U^{0}}\right)}_{D 1}
$$

The index $j$ represents the counterfactual equilibrium after the tax reform, and the index 0 indicates the benchmark equilibrium. $I N C^{0}$ is the "maximum" income in the benchmark, this means

$$
I N C^{0}=w^{0}\left(1-\tau_{w}^{0}\right) \bar{F}+r^{0}\left(1-\tau_{K}^{R^{0}}\right) \bar{K}+B^{0}
$$


Due to its affinity to the tenets of taxation in public finance, D2 can be called the public finance aspect of a green tax reform. Accordingly, D3 and D1 are representing the employment and environmental aspects. D3 is actually not an independent aim but part of the welfare aim. Since D3 plays a very important role in the political debate - in contrast to D2 it is accounted for separately. That way it can be determined, whether D3 and D2 always work in the same direction or whether they bear conflicting targets.

\section{Model simulations}

Our simulation model is accessible under http://brw.zew.de, where the interested reader will find a detailed instruction as well.

Before we investigate the results of a green tax reform with the help of our numerical model, we would like to point out some fundamental restrictions with respect to our quantitative investigations. One never knows if the numerical results are correct. It must be assumed, of course, that the solutions are correct in formal terms, but a wrong model (i.e. wrongly specified with respect to the underlying economics) may have been solved. A small programming error (that can easily creep in) is enough to cause such a dilemma. All this gives rise to more than the usual carefulness with regard to the acceptance and interpretation of simulation models. One may overcome this problem, though, in the following way: as a rule, those policy measures should be simulated first - as a consistency check, so to speak - where qualitative results are already known based on rigorous theroretical analysis. If the simulation model produces different results, it is safe to assume that it is mis-specified. Otherwise, one can proceed with the analysis of reform packages, where results are open in theory. Of course, one can still not be sure that the numerical solutions are "correct". Therefore it is very important that all numerical results can be convincingly explained in economic terms.

\section{a) Consistency Tests}

In this section three consistency tests shall be explained. Best for this purpose are the model variants with full employment (CE-FE, SOE-FE) because the economic intuition is straightforward. The results of the following tax reforms are theoretically non-ambiguous: if the income tax is supplemented with a payroll tax in a revenue-neutral way, the equilibrium values for all quantitative variables remain unchanged. The wage rate merely adjusts, so that the gross wages and the net wages each are identical before and after the tax reform. From the theory of tax incidence we know that it is irrelevant for the equilibrium values of the CE-FE variant who actually pays the tax. What matters is who bears the tax burden. As long as the tax wedge $\theta$ on the labor market remains unchanged, it makes no difference if the tax is levied on households or producers. 
Secondly, we replace the income tax levied in the benchmark equilibrium with respect to the model variants CE-FE and SOE-FE by a tax on the domestic capital stock (i.e. the capital incomes resulting from that) or by a uniform consumption tax. From a theoretical point of view, the results are obvious as well. The taxation of labor income induces distortions on the labor market. These can be completely avoided by switching to the taxation of (domestic) capital income. As the latter is constant (fixed capital endowment) in our static model, a capital income tax works as a lump-sum tax; in other words, capital income taxes are firstbest when we only consider the welfare component D2. Since the distortions on the labor market are reduced, employment, disposable income, consumption demand and overall production rise. As a consequence, the production of energy also rises along with pollutants, resulting in a negative $\mathrm{D} 1(\mathrm{~W})$ and a positive $\mathrm{D} 1(\mathrm{P})$.

Optimal taxation theory suggests that a general consumption tax would be second best in the case of homothetic and weakly separable utility functions. Under welfare aspects (with respect to D2), the general consumption tax is superior to a labor income tax, because the burden of the general consumption tax does not only fall on labor income, but also on (constant) capital income. When switching from the labor income tax to a general consumption tax, part of the tax burden is shifted to fixed capital income. A general consumption tax, hence, corresponds to a labor income tax combined with a lump-sum tax. The distortions on the job market decline, employment rises and so does energy production. The latter induces a decline in D1 as compared to the benchmark equilibrium, but this decline is smaller than it would be for the case of an exclusive capital income tax.

Finally, the exogenous aim of a reduction of overall energy consumption is assumed, just like the German government attempts to do within the framework of the climate protection program. The first dividend $\mathrm{D} 1(\mathrm{P})$ is now given, and therefore $\mathrm{D} 1(\mathrm{~W})$ is fixed as well. For the enforcement of the reduction target, energy consumption in the household and in the production sector should be taxed. It is left open for discussion whether it is advantageous to reach the given emission reduction via an uniform or differentiated energy tax. The decision making criterion lies solely in the change in D2, since D1 is fixed by assumption.

From a theoretical point of view, the result is obvious if in addition to the taxes, which aim at the achievement of the environmental target, first best taxes or transfers are available in order to finance the public good or to refund energy taxes to private households. In that case, energy consumption of the private and production sector should be taxed with equal rates (Pigouvian tax). While the first dividend is positive in welfare terms $(\mathrm{D} 1(\mathrm{~W})>0)$ - which is the main purpose of an energy tax - the second dividend is negative, because these taxes cause allocative distortions in consumption and production. Uniform energy tax rates for the implementation of emission reduction targets are even then unambiguously optimal if the budget account is balanced by a general tax on consumption, which is second best, instead of a first best taxation of the domestic capital stock. 
b) Green Tax Reform in the Case of Full Employment: Energy Taxes versus Income Taxes

The economic effects of revenue neutral tax reforms are not very surprising if, in return to the introduction of energy taxes, first best or second best taxes are reduced. Positive environmental effects are counterbalanced by the negative impacts on the excess burdens of the tax system and unemployment. The question of the impact of a green tax reform on welfare and employment becomes exciting not until third best worlds are taken into consideration. Income taxes are third best taxes in our model. With regard to the excess burdens which are caused, they are definitely inferior when compared to first best taxes on the given capital stock and second best general consumption taxes.

In this section we are going to present and explain some simulation calculations when energy taxes are introduced and taxes on the factor labor are reduced. This is analogue to the expected gains from the German Ecological Tax Reform that came into effect on April 1, 1999. For a better understanding we restrict our focus on the model variant of a closed economy with full employment. In such a scenario it is not important whether the income taxes are tied up to the labor supply or to the labor demand. In the following section we will include the impacts of a green tax reform on unemployment as well.

Primarily, energy taxes should trigger a cutback on the consumption of energy accompanied by a reduction of harmful emissions. A difference has to be made as to whether an emission reduction target is pursued or not. We will consider both cases. With the simulation runs shown in the first part of Table 5, energy tax rates are fixed exogenously, and the reduction of the energy consumption results endogenously. The stated tax rate combinations have been chosen in such a way that they approximately generate the same energy tax revenue.

In the second part of Table 5, we look at given emission reduction target of 5 and 15 per cent alternatively. Those emission reduction targets should be achieved either through uniform or through different energy tax rates for the household and the production sector. In order to do so we fix the ratio of the energy tax rate equal to 1 (equal tax rates), to 0.5 and to 1.5 . A value of 0.5 (1.5) means that the energy tax rate in the production sector is half ( 1.5 times) of that in the household sector. The absolute level of the energy tax rates, as well as of the wage rates necessary for a balanced budget, results endogenously. The lower part of Table 5 contains the simulation results. First of all we will interpret the results for exogenously fixed energy tax rates. We can see that all three of our chosen tax rate combinations exhibit a double dividend. The total energy consumption is reduced by somewhat 5 per cent. At the same time, excess burdens are reduced. With regard to the second dividend, the tax rate combinations of $\tau_{E}^{Y}=19$ and $\tau_{E}^{H}=13$ turn out to be best. An even wider spread of the tax rate is just as useless as an equal taxation of the energy consumption in the household and in the production sector. 
Table 5: $\quad$ Unifom versus differentiated energy taxes: environmental effects and excess burden (GV-VB)

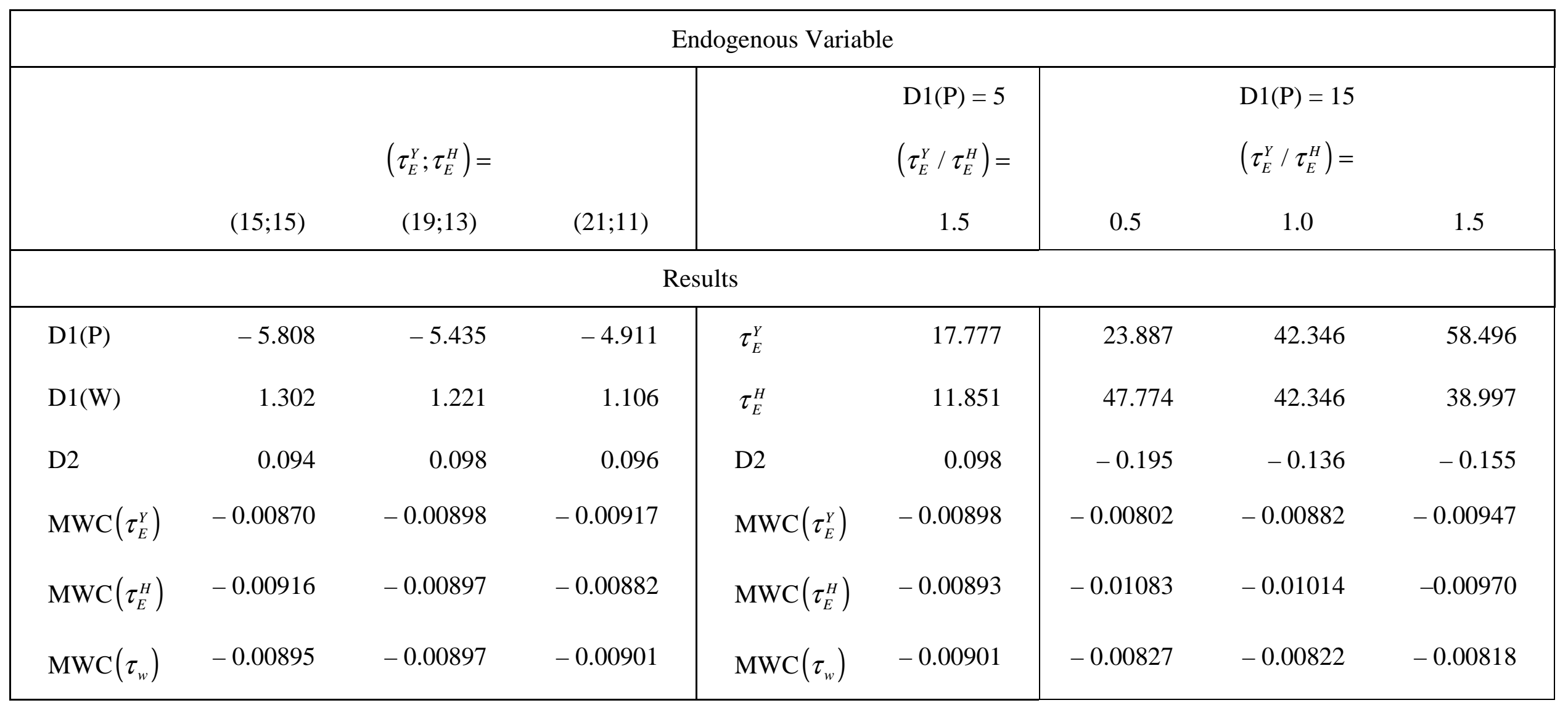


The crucial question, however, is how these results can be interpreted in an economically convincing way. First we need to explain why low energy tax rates generate a double dividend, and why the energy consumption of the production sector should be taxed more heavily than that of the private sector. Both results are surprising at first sight. Having studied the production efficiency theorem by Diamond and Mirrlees (1971) one would expect that distorting taxes in production should be abstained from altogether. However, this result applies to a second-best tax system only - a condition that is not satisfied in the scenarios described in Table 5. In our third best system of a labor income tax efficiency gains can occur due to an intentionally induced distortion in the production sector.

This leaves us to explain the amount and the direction of the differentiation of the tax rates. In order to do so we revert to the marginal cost concept of public funds (MCF); see Schöb (1994) or Snow and Warren (1996). Starting from the newly calculated equilibrium, we raise the public expenditures for goods by a marginal unit and finance the additional public expenditures with various tax instruments available in the respective model set-up. The marginal costs of public funds then specify the costs for the overall economy, which are connected with additional public expenditures for goods by one unit. Accordingly, a value of $(-1.05)$ would mean that 1 additional dollar tax revenue would cause overall economic costs of 1.05 dollars. The costs of 0.05 dollar, which accrue on top of the 1 dollar revenue effect, correspond to the marginal welfare cost of public funds $(\mathrm{MFC}+1)=\mathrm{MWC}$. The structure of tax rates should be chosen in such a way that for each tax MCF or respectively MWC are the same. This means that the rates for taxes with low (high) MWCs should be raised (lowered). Our simulation program calculates the MWCs mechanically. The last three rows of Table 5 show the respective MWC-values. According to public finance aspects, the tax rate combination of $(19 ; 13)$ in addition to a third best income tax is optimal because the MWCs just coincide.

In the second part of Table 5 exogenously given emission reduction targets are analyzed. With a moderate reduction target of 5 per cent (with respect to the overall energy use) a double dividend can also be achieved if the energy tax rates are suitably differentiated. With stricter reduction targets, such as 15 per cent, this is no longer the case. The resulting energy tax rates are so high that the excess burden of the whole tax system would increase (negative D2). Indeed, in that case, uniform energy tax rates would be better than differentiated ones. The economic explanation is that with stricter reduction targets, the environmental objective dominates the public finance objective of minimizing the excess burden. The pursuit of environmental objectives is, thus, best achieved by uniform energy and emission tax rates. The MWCs are given in Table 5 but do not provide any further information with respect to the differentiation of the tax rates. This is so because these indicators merely reflect the public finance marginal excess burden of the tax system but not the dominating environmental objective. 
Next to the reduction of harmful emissions, the relief of the tax burden on labor and the resulting employment gains represent further important objectives of the green tax reform. Table 6 describes the results of some simulation runs in a closed economy with unemployment (CE-UE). In the left part of Table 6 energy tax rates are again fixed exogenously, and in the right part of the Table we can observe the effects of a given reduction target of 15 per cent. In practice, the revenues of a green tax reform are used to reduce the tax on the productive use of labor.

The simulations presented in Table 6 show that a green tax reform is able to create three dividends simultaneously. In all cases considered here three positive effects can be realized: firstly, energy consumption is curtailed and, therefore, harmful emissions are reduced as well; secondly, the efficiency of the tax system is improved due to a reduction of the excess burden and finally, positive employment effects can be observed, i.e. unemployment is reduced.

The examination of Table 6 shows that energy tax rates should be higher in the case of unemployment as opposed to the case with full employment, if the degree of differentiation is comparable. If the productive use of energy is taxed at 19 per cent - as done in Table 5 - but the energy use of private households at 13 per cent on the other hand, the MWCs of labor income taxes turn out higher than those of the energy taxes. It should be noted that, due to concurrent MWCs under a public finance point of view, the structure of the energy tax rates is chosen correctly. Thus, it is appropriate to raise the energy tax rates with an unchanged degree of differentiation and to reduce the income tax.

With reference to D2, the optimal tax rate combination will be reached at 35 and 23 per cent. Given such tax rates, unemployment will be reduced by 1.36 percentage points while overall energy consumption is reduced by 8.5 per cent.

The second part of Table 6 shows that an ambitious reduction target of 15 per cent is compatible with public finance as well as employment objectives. While public finance considerations lead to uniform energy tax rates, employment aspects demand a higher tax on the productive use of energy. Due to the higher energy tax revenues, which are induced by the latter, the tax wedge on the labor market could be reduced even further.

The positive employment effects of energy taxes are explained by our model in such a way that, with a simultaneous reduction of labor taxes, the tax burden on labor is passed on to other factors, i.e. earners of other incomes. Because unemployment transfers are assumed constant in real terms, the green tax reform shifts the tax burden partly onto capital causing a reduction of the real interest rate. 
Table 6: $\quad$ Effects of energy taxes on environment, excess burden and employment (GV-UB)

\begin{tabular}{|c|c|c|c|c|c|c|}
\hline \multicolumn{7}{|c|}{ Endogenous Variable } \\
\hline \multicolumn{3}{|c|}{$\left(\tau_{E}^{Y} ; \tau_{E}^{H}\right)=$} & & \multicolumn{3}{|c|}{$\begin{array}{l}\mathrm{D} 1(\mathrm{P})=15 \\
\left(\tau_{E}^{Y} / \tau_{E}^{H}\right)=\end{array}$} \\
\hline & $(19 ; 13)$ & $(35 ; 23)$ & & 0.5 & 1.0 & 1.5 \\
\hline \multicolumn{7}{|c|}{ Results } \\
\hline $\mathrm{D} 1(\mathrm{P})$ & -4.815 & -8.488 & $\tau_{E}^{Y}$ & 25.790 & 45.947 & 63.687 \\
\hline D2 & 0.326 & 0.389 & $\tau_{E}^{H}$ & 51.579 & 45.947 & 42.458 \\
\hline D3 & -0.902 & -1.359 & $\tau_{w}$ & 13.788 & 11.683 & 10.076 \\
\hline $\operatorname{MWC}\left(\tau_{E}^{Y}\right)$ & -0.01095 & -0.01116 & D2 & 0.142 & 0.242 & 0.237 \\
\hline $\operatorname{MWC}\left(\tau_{E}^{H}\right)$ & -0.01091 & -0.01113 & D3 & -1.624 & -1.788 & $-1,874$ \\
\hline $\operatorname{MWC}\left(\tau_{w}\right)$ & -0.01186 & -0.01114 & & & & \\
\hline
\end{tabular}


The results cannot be generalised without restrictions. It is easy to find tax reform scenarios which are more advantageous than a green tax reform with respect to D2 and D3. And it can be shown that a green tax reform causes a higher excess burden and raises unemployment if it is used to complement a consumption tax. It is left to the reader to implement such reform scenarios and to interpret the results economically.

\section{Conclusion}

Our simulation model enables us to determine the environmental, efficiency and employment effects of a green tax reform for different variants of the general benchmark equilibrium. It has been shown that a sensibly designed green tax can drop three dividends simultaneously if considered in third best worlds (and only in these). The green tax can be used to improve the quality of the environment, the efficiency of the tax system and it can cause positive employment effects. One should be careful, though, to generalize and apply our results to the real world without reservation. For such purposes, our model is far too simple. 


\section{References}

Bovenberg, A. L. and R. A. de Mooij (1994a): Environmental Levies and Distortionary Taxation. American Economic Review 84, 1085-1089.

Bovenberg, A. L. and R. A. de Mooij (1994b): Environmental Taxes and Labor-Market Distortions. European Journal of Political Economy 10 (4), 655-684.

Bovenberg, A.L. (1999): Green tax reforms and the double dividend: An updated reader's guide. International Tax and Public Finance 6, 421- 424.

Bovenberg, A.L. and L. H. Goulder (1996): Optimal Environmental Taxation in the Presence of Other Taxes: General Equilibrium Analyses. American Economic Review 86 (4), 985-1000.

Bovenberg, A.L. and L. H. Goulder (1997): Costs of Environmentally Motivated Taxes in the Presence of Other Taxes: General Equilibrium Analyses. National Tax Journal 50 (1), 59-87.

Diamond, P. A. and J. A. Mirrless (1971): On Optimal Taxation and Public Production. I: Production Efficiency. American Economic Review 51, 8-27; II: Tax Rules, 261-278.

Goulder, L. H. (1992): Carbon Tax Design and U.S. Industry Performance Environmental Taxation and the Double Dividend: A Readers' Guide. In: Poterba, J. M. (ed.): Tax Policy and the Economy, Cambridge, Mass., Vol. 6, 59-104.

Goulder, L. H. (1994): Energy Taxes: Traditional Efficiency Effects and Environmental Implications. In: Poterba, J. M. (ed.): Tax Policy and the Economy, Cambridge, Mass., Vol. 8, 105-158.

Goulder, L. H. (1995): Environmental Taxation and the Double Dividend: A Readers' Guide. International Tax and Public Finance 2, 157-183.

Hutton, J. and A. Ruocco (1999): Tax Reform and Employment in Europe. International Tax and Public Finance 6, 263-288.

Johansson, P.-O. (1987): The Economic Theory and Measurement of Environmental Benefits. Cambridge etc.

King, B. (1985): What is a SAM? In: Pyatt, G. and J. I. Round (eds.), Social Accounting Matrices: A Basis for Planning. Washington D. C.: The World Bank.

Koskela, E. and R. Schöb (1999): Alleviating Unemployment: The Case for Green Tax Reforms. European Economic Review. 43, 1723 - 1746.

Mansur, A. and J. Whalley (1984): Numerical Specification of Applied General Equilibrium Models: Estimation, Calibration, and Data. In: Scarf, H. E. and J. B. Shoven (eds.), Applied General Equilibrium Analysis, Cambridge etc., 69-127.

Oates, W. E. (1995): Green taxes: can we protect the environment and improve the tax system at the same time?. Southern Economic Journal 61 (4), 915-922

Pearce, D.W. (1991): The Role of Carbon Taxes in Adjusting to Global Warming. Economic Journal 101, 938-948.

Schneider, K. (1997): Involuntary Unemployment and Environmental Policy: The Double Dividend Hypothesis. Scandinavian Journal of Economics 99, 45-59. 